\title{
Development of a Nanotechnology Based Biomedicine RISUG-M as a Female Contraceptive in India
}

Rama Kant Singh*, Falgun Wanganuji Bansode, Sharad Sharma, Poonam Singh, Smrati Bhadauria, Sarika Singh and Chandishwar Nath

Divisions of Toxicology and Endocrinology, CSIR-Central Drug Research Institute, Jankipuram Extension, Lucknow-226031, India

\begin{abstract}
Background and objectives: The aim of this study was to assess the toxic effect of the newly developed contraceptive RISUG-M in female Charles Foster rats.

Methods: Young, healthy and nulliporus female rats of Charles Foster strain were employed in the study. They were randomly assigned to two groups, control and treated each consisting of female animals. The contraceptive RISUG-M was injected in the fallopian tube of the treated group rats while only vehicle was injected in control group rats' fallopian tube and observed for a period of 14 days. Initial and final body weights and food/water consumption of the animals were recorded. The haematological and biochemical parameters were analyzed. At the end of the study all the animals were sacrificed and necropsied, the organ weight was taken and their histopathological slides were prepared for microscopic examination.
\end{abstract}

Results: Body weight, food and water consumption, haematology, biochemistry, absolute and relative organ weights did not show any significant change and were well within the limit of normalcy. General health check-up, mortality, gross and microscopic examination of organs and tissues also did not reveal any sign of toxicity.

Interpretation and conclusions: From the toxicity point of view this newly developed injectable contraceptive RISUG-M does not have any adverse effect and is safe to use.

Keywords: RISUG-M; Contraceptive; Toxicity; Nanoparticles; Sperm

\section{Introduction}

In India, a new cuproferrogel contraceptive drugiron-copper-styrene maleic anhydride-dimethyl sulphoxide $\left(\mathrm{Fe}_{3} \mathrm{O}_{4}\right.$-Cu-SMA-DMSO) has been developed by Prof. Guha and his team at I.I.T. Kharagpur. Earlier experiments conducted on albino rats proved spermicidal activity of RISUG and its non-toxicity [1,2] and teratogenic safety [3] have also confirmed. After injecting RISUG, as sperm come into contact with the polymer, the positive and the negative charges on the polymer surface causes significant damage to the acrosome and its content and causes the surface of sperm burst, making it immotile and incapable to fertilize an egg [4-6]. RISUG-M is an advancement of the contraceptive RISUG and consist of a co-polymer styrene maleic anhydride (SMA), magnetic particles: iron oxide (8-12\%), electrically conductive particles: copper (3-8\%) dissolved in 99\% pure dimethylsulphoxide (DMSO) [7]. It is long time effective, non-invasively reversible and controllable, antimicrobial as anti HIV and prostate cancer preventive contraceptive method for both male and female [8,9]. Due to large surface-to-volume ratio and magnetic properties, the contraceptive magnetic nanoparticles tend to aggregate and adsorb to plasma proteins [10] but the use of SMA cause surface coverage of magnetic particles $\mathrm{Fe}_{3} \mathrm{O}_{4}$ with the safe and effective polymer which significantly increases the stability and ensure proper distribution by eliminating aggregation and adsorption of proteins $[11,12]$. From the well known phenomenon that both the concentration of magnetic particles and the cross - linking density of the ferrogels play a crucial role in the magnetoelasticity [13], it can be drawn that in vivo control of this contraceptive is due to change of the electricity of ferromagnetic polymeric compound with magnetization [14]. On applying magnetic field, ferrogels acquires a net magnetic moment due to ordered orientation of particles in the field direction which is reversible and the material reverts to randomized orientation on switching off the external field [15]. Thus the use of magnetic iron oxides have two advantages - low toxic to human beings and target drugs or antibodies to a specific cell by applying magnetic field [16]. Moreover, copper particles add two functions to the contraceptive drug - its intrinsic high electrical conductivity makes the overall compound electrically conductive which can be reverted to facilitate removal for restoration of fertility. Secondly, it displaces zinc from the sperm membrane and head by itself which accounts in decreased motility of spermatozoa and lowers the fertilizing potential of the sperm [1719]. Similarly, it also lowers the fertility of ovum by displacement of proteins [19]. Once the RISUG-M is inserted into the uterus through rubber tube, the semi-solid drug is managed to get positioned in the fallopian tube by applying radio frequency field from outside. The drug when comes in the contact with water molecules and amino acids, it develops an electric charge and nullifies the sperms and ova electric charges, therefore, making them inactive and incapable of fertilization. The major advantage of this method is that the drug can be flushed out whenever required. The objective of the present study is toxicity evaluation of this new injectable antifertility agent RISUG-M in rats.

It's called RISUG: Reversible Inhibition of Sperm under Guidance. It involves a minor surgical procedure in which the vas deferens is exposed and pulled outside the scrotum by the same techniques used for a vasectomy. A copolymer, powdered styrene maleic anhydride (SMA,

*Corresponding author: Rama Kant Singh, Division of Toxicology, CSIR-CDRI Jankipuram extension, Lucknow-226031, India, Tel: 91-9984941595; E-mail: rktox@yahoo.com, rk_singh@cdri.res.in

Received January 09, 2015; Accepted May 18, 2015; Published June 02, 2015

Citation: Singh RK, Bansode FW, Sharma S, Singh P, Bhadauria S, et al. (2015) Development of a Nanotechnology Based Biomedicine RISUG-M as a Female Contraceptive in India. J Nanomed Nanotechnol 6: 297. doi:10.4172/21577439.1000297

Copyright: $\odot 2015$ Singh RK, et al. This is an open-access article distributed under the terms of the Creative Commons Attribution License, which permits unrestricted use, distribution, and reproduction in any medium, provided the original author and source are credited. 
for which the method was previously named) combined with dimethyl sulfoxide (DMSO) is then injected into the vas deferens. The polymer coats the walls of the vas and kills the sperm as they swim by. The mechanism is not understood, but the developer thinks the polymer's mosaic of positive and negative charges causes the membranes of the sperm to burst, rendering them immotile [20].

\section{Materials and Methods}

\section{Animals}

A total of 40 young, healthy, nulliparous and non-pregnant female rats of Charles Foster strain were issued by the Division Laboratory Animals, CDRI, and Lucknow and were acclimatized for 7 days to the laboratory conditions. Throughout the study, a sequence of 12 hour cycles of light and darkness was maintained in the room with the help of artificial lighting. The animals were fed with laboratory pellet diet and water $a d$ lib. The ethical approval was given by Institutional Animal Ethics Committee (IAEC), Delhi, India and Committee for the Purpose of Control and Supervision of Experiments on Animals (CPCSEA), New Delhi, India.

\section{Test compound}

The test compound RISUG-M, a female contraceptive was supplied by Dr. Sujoy Kumar Guha, Professor of Biomedical Engineering at the School of Medical Science and Technology, Indian Institute of Technology Kharagpur, India.

\section{Experimental design}

On the basis of initial health check-up, 30 rats were employed in the study and were randomly divided into two groups, each consist of 15 female rats. Group II was taken as treated group and RISUG-M was inserted into the fallopian tube of the rats. Group I was taken as control and only vehicle was inserted into the fallopian tube of the rats. Body weight, food and water consumption were recorded at different time interval for a total period of 14 days. Haematology was done initially and terminally. At the end of the study all the animals were sacrificed and blood samples were collected for biochemical analysis. The organs were taken out, recorded the absolute and relative organ weight. The histopathological slides of the organs and tissues were prepared for microscopic examination.

\section{Statistical analysis}

Data were expressed as mean \pm S.D. Data comparisons were carried out to compare means of the treated group with that of control.

\section{Results}

\section{General health check-up and mortality}

Animals belonging to control and treated group were generally active and healthy throughout the period of the study. No mortality was seen in either control or treated group rats.

\section{Body weight record}

There was a uniform and comparable gain in body weight among the animals of both the groups (Table 1).

\section{Food and water consumption record}

Measurement of the initial and leftover water and pellets given to the animals did not revealed significant change in the average 24-hour water and food intake of animals in the control and treated groups

\begin{tabular}{|l|c|c|}
\hline \multirow{2}{*}{ Group No. } & \multicolumn{2}{|c|}{ Body Weight (gm) } \\
\cline { 2 - 3 } & Initial & Final \\
\hline Group No. I & $172.73 \pm 10.87$ & $192.53 \pm 14.60$ \\
\hline Group No. II & $172.33 \pm 12.10$ & $175.00 \pm 13.11$ \\
\hline
\end{tabular}

Table 1: Body Weight of Rats.

\begin{tabular}{|l|l|l|}
\hline \multirow{2}{*}{ Group No. } & \multicolumn{2}{|l|}{ Average Food Intake (gm/day/rat) } \\
\hline & Initial & Final \\
\hline Group No. I & 8.37 & 8.15 \\
\hline Group No. II & 8.90 & 8.89 \\
\hline
\end{tabular}

Table 2: Average Food Intake of Rats.

\begin{tabular}{|l|l|l|}
\hline \multirow{2}{*}{ Group No. } & \multicolumn{2}{|l|}{ Average Water Intake (ml/day/rat) } \\
\hline & Initial & Final \\
\hline Group No. I & 15.10 & 14.50 \\
\hline Group No. II & 15.71 & 16.40 \\
\hline
\end{tabular}

Table 3: Average Water Intake of Rats.

(Tables 2 and 3).

\section{Haematology}

There were no significant changes found in any of the haematological parameters of either group animals. All the parameters were well within the limit of normalcy (Table 4).

\section{Biochemistry}

The animals of both the groups did not showed any significant variation in the biochemical parameters of kidney, liver and general metabolic functions (Table 5).

\section{Absolute and relative organ weights}

Mean values of absolute and relative weights of brain, heart, kidneys, adrenals, spleen, liver, lung, uterus, fallopian tubes and ovary showed no significant variations and remained within the limits of normalcy in comparison to the control animals (Tables 6 and 7).

\section{Histopathological examination}

The microscopic examination of the slides of the organs and tissues did not reveal any pathological change.

\section{Discussion}

Sperm morphology is a significant factor for fertilization and pregnancy, especially the anterior part of the sperm i.e. - acrosome and any change in it can cause impairment in the gamete interaction [6]. Thus, any morphological change in the sperm cell is one of the most important aspects while developing a contraceptive [21]. There are three important key enzymes - 5'-nucleotidase (5'-NT), hyaluronidase and proacrosin-acrosin system which facilitate sperm-oocyte interaction. On treatment with RISUG-M, it causes excessive loss of plasma membrane-associated enzyme 5'-NT (82\%) and hyaluronidase (90\%) from the acrosomal membrane and inactivation of the active form of acrosin which results in complete degeneration of the acrosomal membrane that indicates RISUG-M is an effective contraceptive [6]. This was also confirmed by performing a comparative study employing High Resolution Transmission Electron Microscopy (HRTEM), Field Emission Scanning Electron Microscopy (FESEM), Atomic Force Microscopy (AFM), Scanning Electron Microscopy (SEM)-X ray microanalysis, Phase Contrast Microscopy and Fluorescent Activated Cell Sorting (FACS) [7]. The new implant device RISUG-M gives better spermicidal action than RISUG, detectable by X-ray and magnetic 
Citation: Singh RK, Bansode FW, Sharma S, Singh P, Bhadauria S, et al. (2015) Development of a Nanotechnology Based Biomedicine RISUG-M as a Female Contraceptive in India. J Nanomed Nanotechnol 6: 297. doi:10.4172/2157-7439.1000297

Page 3 of 4

\begin{tabular}{|c|c|c|c|c|c|c|c|c|c|c|c|}
\hline \multirow{3}{*}{$\begin{array}{l}\text { Group } \\
\text { No. }\end{array}$} & \multirow{2}{*}{\multicolumn{4}{|c|}{ Red Blood Cells }} & \multicolumn{6}{|c|}{ White Blood Cells } & \multirow{3}{*}{$\begin{array}{l}\text { Platelets } \\
\left(\times 10^{3} / \mathrm{mm}^{3}\right)\end{array}$} \\
\hline & & & & & \multirow[b]{2}{*}{$\begin{array}{l}\text { TLC } \\
\left(\times 10^{3} / \mathrm{mm}^{3}\right)\end{array}$} & \multicolumn{5}{|c|}{ DLC (\%) } & \\
\hline & $\begin{array}{l}\text { Hgb } \\
(g \%)\end{array}$ & \begin{tabular}{|l|l|} 
T - R B C Hct \\
$\left(\times 10^{6} / \mathrm{mm}^{3}\right)$ & $(\%)$ \\
\end{tabular} & $\begin{array}{l}\text { MCV } \\
\left.\text { (micron }^{3}\right)\end{array}$ & $\begin{array}{l}\mathrm{MCHC} \\
(\mathrm{g} \%)\end{array}$ & & $\mathbf{P}$ & L & $\mathbf{M}$ & $E$ & B & \\
\hline
\end{tabular}

Group Initial $11.47 \pm 0.476 .11 \pm 0.42 \quad 30.86 \pm 1.8950 .57 \pm 1.6937 .23 \pm 1.81 \quad 12.81 \pm 3.41 \quad 9.20 \pm 3.23 \quad 84.60 \pm .67 \quad 3.20 \pm 0.68 \quad 2.47 \pm 2.390 .53 \pm 0.52 \quad 289.40 \pm 24.06$

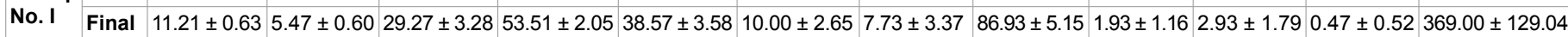

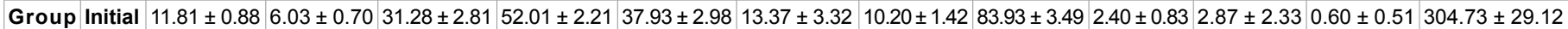
\begin{tabular}{l|l|l|l|l|l|l|l|l|l|l|l|l} 
No. II Final & $11.95 \pm 0.75$ & $5.38 \pm 0.42$ & $29.07 \pm 2.15$ & $53.79 \pm 2.32$ & $41.09 \pm 1.94$ & $9.67 \pm 2.65$ & $6.40 \pm 3.02$ & $88.47 \pm 4.26$ & $2.40 \pm 0.91$ & $2.33 \pm 1.76$ & $0.33 \pm 0.49$ & $352.33 \pm 136.49$
\end{tabular}

$\mathrm{Hgb}=$ Haemoglobin, T-RBC=Total Red Blood Cell, Hct=Haematocrit, MCV=Mean corpuscular volume, MCHC=Mean corpuscular haemoglobin concentration, TLC=Total leucocyte count, DLC=Differential leucocyte count, $\mathrm{P}=$ =Polymorph, L=Leucocyte, $M=$ Monocyte, E=Eosinophil, B=Basophil.

Table 4: Haematology of Rats.

\begin{tabular}{|c|c|c|c|c|c|c|c|c|c|c|c|c|c|}
\hline \multirow{2}{*}{$\begin{array}{l}\text { Group } \\
\text { No. }\end{array}$} & \multicolumn{5}{|c|}{ General Metabolic Functions } & \multicolumn{4}{|c|}{ Liver Functions } & \multicolumn{4}{|c|}{ Kidney Functions } \\
\hline & GLU (mg/dl) & $\begin{array}{l}\text { CHOL (mg/ } \\
\text { dl) }\end{array}$ & $\begin{array}{l}\text { TG } \\
\text { (mg/dl) }\end{array}$ & TP (mg/dl) & $\begin{array}{l}\text { ALB (mg/ } \\
\text { dl) }\end{array}$ & ALT (U/L) & AST (U/L) & ALP (U/L) & $\begin{array}{l}\text { TBIL (mg/ } \\
\text { dl) }\end{array}$ & BUN (mg/dl) & $\begin{array}{l}\text { C R T N } \\
\text { (mg/dl) }\end{array}$ & $\begin{array}{l}\text { Ca (mg/ } \\
\text { dl) }\end{array}$ & $P(\mathrm{mg} / \mathrm{dl})$ \\
\hline $\begin{array}{l}\text { Group } \\
\text { No. I }\end{array}$ & $100.04 \pm 9.90$ & $66.87 \pm 9.01$ & $37.18 \pm 18.53$ & $7.71 \pm 0.56$ & $3.49 \pm 0.32$ & $70.55 \pm 15.79$ & $189.08 \pm 78.40$ & $686.42 \pm 185.17$ & $0.17 \pm 0.05$ & $14.49 \pm 2.11$ & $0.53 \pm 0.03$ & $7.08 \pm 0.60$ & $6.99 \pm 1.04$ \\
\hline \multirow[t]{2}{*}{$\begin{array}{l}\text { Group } \\
\text { No. II }\end{array}$} & $96.37 \pm 22.43$ & $61.38 \pm 7.84$ & $39.47 \pm 8.79$ & $7.62 \pm 0.88$ & $3.28 \pm 0.38$ & $61.67 \pm 11.62$ & $192.79 \pm 51.79$ & $545.36 \pm 198.81$ & $0.16 \pm 0.06$ & $22.42 \pm 5.22$ & $0.57 \pm 0.04$ & $6.13 \pm 0.76$ & $7.60 \pm 1.42$ \\
\hline & & & & & & & GLU & & & & & & \\
\hline
\end{tabular}

$\mathrm{GLU}=\mathrm{Glucose}, \mathrm{CHOL}=$ Cholesterol, $\mathrm{TG}=$ Triglyceride, $\mathrm{TP}=$ Total Protein, $\mathrm{ALB}=\mathrm{Albumin}, \mathrm{ALT}=\mathrm{Alanine}$ aminotransferase, $\mathrm{AST}=\mathrm{Aspartate}$ aminotransferase, $\mathrm{ALP}=\mathrm{Alkaline}$ Phosphatase, $\mathrm{TBIL}=$ Total Bilirubin, $\mathrm{BUN}=\mathrm{Blood}$ Urea Nitrogen, $\mathrm{CRTN}=\mathrm{Creatinine}, \mathrm{Ca}=\mathrm{Calcium}, \mathrm{P}=\mathrm{Phosphorus}$.

Table 5: Terminal Biochemistry of Rats.

\begin{tabular}{|c|c|c|c|c|c|c|c|c|c|c|}
\hline \multirow{2}{*}{ Group No. } & \multicolumn{2}{|l|}{ Adrenal (gm) } & \multirow[t]{2}{*}{ Brain(gm) } & \multirow[t]{2}{*}{ Gonads(gm) } & \multirow[t]{2}{*}{ Heart(gm) } & \multicolumn{2}{|l|}{ Kidney(gm) } & \multirow[t]{2}{*}{ Liver(gm) } & \multirow[t]{2}{*}{ Lungs(gm) } & \multirow[t]{2}{*}{ Spleen(gm) } \\
\hline & Right & Left & & & & Right & Left & & & \\
\hline Group No. I & $0.03 \pm 0.01$ & $0.03 \pm 0.01$ & $1.65 \pm 0.15$ & $0.63 \pm 0.21$ & $0.74 \pm 0.08$ & $0.78 \pm 0.12$ & $0.76 \pm 0.11$ & $6.64 \pm 0.62$ & $1.35 \pm 0.26$ & $0.85 \pm 0.13$ \\
\hline Group No. II & $0.03 \pm 0.01$ & $0.03 \pm 0.01$ & $1.73 \pm 0.13$ & $0.49 \pm 0.10$ & $0.75 \pm 0.05$ & $0.72 \pm 0.10$ & $0.70 \pm 0.06$ & $5.32 \pm 0.50$ & $1.26 \pm 0.26$ & $0.74 \pm 0.12$ \\
\hline \multirow{2}{*}{ Group No. } & \multicolumn{2}{|l|}{ Adrenal (gm) } & Brain(gm) & Gonads(gm) & Heart(gm) & \multicolumn{2}{|l|}{ Kidney(gm) } & Liver(gm) & Lungs(gm) & Spleen(gm) \\
\hline & Right & Left & & & & Right & Left & & Right & Left \\
\hline Group No. I & $0.02 \pm 0.0$ & $0.02 \pm 0.0$ & $0.86 \pm 0.11$ & $0.33 \pm 0.11$ & $0.38 \pm 0.04$ & $0.40 \pm 0.05$ & $0.39 \pm 0.04$ & $3.46 \pm 0.34$ & $0.70 \pm 0.13$ & $0.44 \pm 0.07$ \\
\hline Group No. II & $0.02 \pm 0.0$ & $0.02 \pm 0.0$ & $0.99 \pm 0.10$ & $0.28 \pm 0.05$ & $0.43 \pm 0.03$ & $0.41 \pm 0.07$ & $0.40 \pm 0.05$ & $3.04 \pm 0.25$ & $0.72 \pm 0.12$ & $0.43 \pm 0.08$ \\
\hline
\end{tabular}

Table 7: Relative Organ Weight of Rats.

imagining and it's in vivo distribution can be controlled outside the body with the application of an external pulsed magnetic field (PMF) [21]. The modification in the form of RISUG to RISUG-M does not alter the effect on sperm as low concentration of iron oxide and copper are added. The only difference is that the combination of the iron oxide-copper-PMF enhances the spermicidal action and further the contraceptive efficacy of the compound [19]. A disadvantage of magnetic nanoparticles is that they are not easily destroyed or inactivated by the cells and thus the persistent particles may cause cell damage and death. But in the case of RISUG-M, no such hazard exists as the magnetic nanoparticles present in it are coated with a non-toxic polymer styrene maleic anhydride [7]. When RISUG-M is injected and PMF is applied, the iron oxide enters the sperm membrane forming a mosaic structure enveloped with copper micro strands which creates a large surface of electrical charge interaction for the distribution of sperms and thus enhanced the spermicidal action in a sustained manner [19]. Though, the gonad weight analysis and sperm anomaly assay proved in vivo safety and effectiveness of RISUG-M in rats [22], the drug is further evaluated for any possible sign of toxicity before applying to humans despite the moderate amount of iron oxide is used which does not adversely affect the sperm functionality $[23,24]$. The data in this study indicates that $\mathrm{SMA}-\mathrm{Fe}_{3} \mathrm{O}_{4}-\mathrm{Cu}-\mathrm{DMSO}$, composite name RISUG-M is safe and therefore, opens pathway to use RISUG-M as an effective contraceptive drug in future.

\section{Acknowledgements}

The authors are thankful to Prof. Sujoy K. Guha for kindly providing the
RISUG-M for the above study and for the research grant in the form of collaborative research project to our institute.

\section{References}

1. Sethi N, Srivastava RK, Singh RK (1989) Safety evaluation of a male injectable antifertility agent, styrene maleic anhydride, in rats. Contraception 39: 217-226.

2. Sethi N, Srivastava RK, Singh RK, Bhatia GS, Sinha N (1990) Chronic toxicity of styrene maleic anhydride, a male contraceptive, in rhesus monkeys (Macaca mulatta). Contraception 42: 337-347.

3. Sethi N, Srivastava RK, Nath D, Singh RK (1992) Teratological evaluation of an injectable male antifertility agent, styrene maleic anhydride, in rats. Int $\mathrm{J}$ Fertil 37: 183-187.

4. Guha SK, Singh G, Ansari S, Kumar S, Srivastava A, et al. (1997) Phase Il clinical trial of a vas deferens injectable contraceptive for the male. Contraception 56: 245-250.

5. Sharma U, Chaudhury K, Jagannathan NR, Guha SK (2001) A proton NMR study of the effect of a new intravasal injectable male contraceptive RISUG on seminal plasma metabolites. Reproduction 122: 431-436.

6. Chaudhury K, Bhattacharyya AK, Guha SK (2004) Studies on the membrane integrity of human sperm treated with a new injectable male contraceptive. Hum Reprod 19: 1826-1830.

7. Jha RK, Jha PK, Rana SVS, Guha SK (2009) Spermicidal action of styrene maleic anhydride polyelectrolyte in combination with magnetic and electrically conductive particles. Inter J Pharm 5: 1-12.

8. Guha SK (2005) RISUG (reversible inhibition of sperm under guidance)-an antimicrobial as male vas deferens implant for HIV free semen. Med Hypotheses 65: 61-64.

9. Sharma S, Sen P, Mukhopadhyay SN, Guha SK (2003) Microbicidal male contraceptive - RISUG induced morphostructural damage in E.coli. Colloids Suface 32: 43-50. 
Citation: Singh RK, Bansode FW, Sharma S, Singh P, Bhadauria S, et al. (2015) Development of a Nanotechnology Based Biomedicine RISUG-M as a Female Contraceptive in India. J Nanomed Nanotechnol 6: 297. doi:10.4172/2157-7439.1000297

10. Zhang Y, Kohler N, Zhang M (2002) Surface modification of superparamagnetic magnetite nanoparticles and their intracellular uptake. Biomaterials 23: 15531561.

11. Gruttner C, Rudershausen S, Teller J (2001) Improved properties of magnetic particles by combination of different polymer materials as particle matrix. $\mathrm{J}$ Magn Magn Mater 225: 1-7.

12. Gupta AK, Curtis A (2002) Surface modification of superparamagnetic iron oxide nanoparticles and their intracellular uptake. Eur Cells Mater 4: 101-102.

13. Zrinyi M, Barsi L, Buki A (1997) Ferrogel: a new magneto-controlled elastic medium. Polymer Gels and Networks 5: 415-427.

14. Gaganidze E, Esquinazi P, Ziese M (2000) Vibrating ferromagnets in a magnetic field. J Alloy 310: 144-152.

15. Lebedev VT, Torok G, Cser L, Buyanov Al, Revelskaya LG, et al. (1999) Magnetic phase ordering in ferrogels under applied field. $\mathrm{J}$ Magn Magn Mater 201: 136-139.

16. Lübbe AS, Bergemann C, Riess H, Schriever F, Reichardt P, et al. (1996) Clinical experiences with magnetic drug targeting: a phase I study with 4 '-epidoxorubicin in 14 patients with advanced solid tumors. Cancer Res 56: 4686-4693.
17. Maynard PV, Elstein M, Chandler JA (1975) The effect of copper on the distribution of elements in human spermatozoa. J Reprod Fertil 43: 41-48.

18. Roblero L, Guadarrama A, Lopez T, Zegers-Hochschild F (1996) Effect of copper ion on the motility, viability, acrosome reaction and fertilizing capacity of human spermatozoa in vitro. Reprod Fertil Dev 8: 871-874.

19. Jha RK, Jha PK, Guha SK (2009) Smart RISUG: a potential new contraceptive and its magnetic field-mediated sperm interaction. Int J Nanomedicine 4: 55-64

20. https://www.sciencebasedmedicine.org/risug-birth-control-for-men/

21. Cheng CY, Mruk DD (2002) Cell junction dynamics in the testis: Sertoli-germ cell interactions and male contraceptive development. Physiol Rev 82: 825874

22. Guha SK (2007) An improved reversible contraceptive for male and female.

23. Ben-David Makhluf S, Qasem R, Rubinstein S, Gedanken A, Breitbart H (2006) Loading magnetic nanoparticles into sperm cells does not affect their functionality. Langmuir 22: 9480-9482.

24. Hofmann H, Juillerat J, Petri-Fink A, Chastellain M (2004) Development of biocompatible functionalized superparamagnetic iron oxide nanoparticles for human cancer cell uptake. Eur Cell Mater 7: 14 